\title{
Thiourea Derivatives as Brønsted Acid Organocatalysts
}

\author{
Ádám Madarász, ${ }^{\dagger}$ Zsolt Dósa, ${ }^{\dagger}$ Szilárd Varga, ${ }^{\dagger *}$ Tibor Soós, $^{\dagger}$ Antal Csámpai, ${ }^{\ddagger}$ Imre Pápai ${ }^{\dagger *}$ \\ ${ }^{\dagger}$ Institute of Organic Chemistry, Research Centre for Natural Sciences, Hungarian Academy of Sciences, H-1117 Budapest, \\ Magyar tudósok körútja 2, Hungary \\ † Institute of Chemistry, Eötvös Loránd University, P. O. B. 32, H-1518 Budapest-112, Hungary
}

\begin{abstract}
Combined computational-experimental studies were carried out to parallel two mechanistic models for tetrahydropyranylation of alcohols catalyzed by Schreiner's thiourea. The results challenge the common mechanistic view that the catalytic effect is related to stabilizing double hydrogen-bonding interactions between the thiourea and the alcohol, which promote the attack on 3,4-dihydro-2H-pyran (DHP; HB mechanism). In the alternative mechanism we propose, thiourea acts as a Brønsted acid, protonating DHP to form an oxacarbenium ion, which reacts with the alcohol (BA mechanism). Computations point to clear preference of transition states associated with the BA mechanism and, accordingly, predict similar catalytic activity for $N$ methylated thiourea and thiouracil. These predictions are confirmed experimentally. Reactions with deuterated alcohols yield both syn and anti products, providing further support for the Brønsted acid mechanism.
\end{abstract}

Keywords: organocatalysis, thiourea, mechanism, hydrogen bonding interactions, acid-base catalysis, computational analysis, tetrahydropyranylation

\section{INTRODUCTION}

Hydrogen bond catalysis has emerged as a fruitful strategy in organic synthesis, particularly in enantioselective organocatalysis. ${ }^{1}$ The organocatalytic approach employs small chiral organic molecules often involving hydrogen bond donor functionalities to promote asymmetric transformations. Thiourea derivatives represent a privileged class of organocatalysts developed along these lines. ${ }^{2}$ The catalytic activity of these compounds is generally associated with the ability of forming double H-bonds with substrates, which can favorably preorganize and activate the reacting partners. ${ }^{3}$ Multiple H-bonding interactions can also significantly stabilize anionic species and transition states (TSs) involved in the reaction, thus allowing kinetically more advantageous pathways.

The symmetric thiourea compound $N, N$ '-bis[3,5-bis $\left(\mathrm{CF}_{3}\right)$ phenyl]thiourea (1) introduced by Wittkopp and Schreiner is considered as a prototype for H-bond-assisted organocatalysis (Chart 1). Seminal studies demonstrated the enhanced catalytic effect of this electron-deficient thiourea derivative in Diels-Alder reactions and highlighted the potential of thiourea catalysis. ${ }^{4}$ In subsequent studies, compound $\mathbf{1}$ was shown to be an efficient catalyst or co-catalyst in a wide range of organic transformations. ${ }^{5,6}$ Quite remarkably, the combination of electron-deficient thioureas with various amines in a chiral scaffold led to the development of bifunctional organocatalysts. ${ }^{7}$ The most frequently used catalysts of this type (e.g., Takemoto's catalyst ${ }^{8}$ and cinchona-based thiourea derivatives, ${ }^{9}$ see Chart 1$)$ include a $N$-[3,5-bis $\left(\mathrm{CF}_{3}\right)$ phenyl]-substituted thiourea unit, which is known to act as double H-bond donor in the bifunctional mechanism. ${ }^{10,11}$ 
<smiles>FC(F)(F)c1cc(NC(=S)Nc2cc(C(F)(F)F)cc(C(F)(F)F)c2)cc(C(F)(F)F)c1</smiles>

1<smiles>CN(C)C1CCCC[C@H]1NC(=S)Nc1cc(C(F)(F)F)cc(C(F)(F)F)c1</smiles>

2

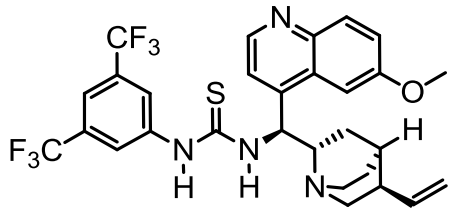

3

Chart 1: $N, N$-bis[3,5-bis $\left(\mathrm{CF}_{3}\right)$ phenyl]thiourea (1) (referred to as Schreiner's thiourea) and two representatives of thiourea-based bifunctional amine catalysts (Takemoto's catalyst (2) and epi-quinine catalyst (3)).

Among the variety of reactions catalyzed by Schreiner's thiourea, acetalization of carbonyl compounds ${ }^{12}$ and tetrahydropyranylation of hydroxyl functionalities ${ }^{13}$ were found to be particularly efficient (Scheme 1). The catalyst loading in these processes could be reduced far below $1 \%$, which is quite unusual in organocatalysis. The reactivity of catalyst $\mathbf{1}$ in these transformations was interpreted in terms of oxyanion stabilization via double $\mathrm{H}$ bonding interactions. Tetrahydropyranylation of alcohols and phenols is a common and well-established protection strategy in synthetic chemistry, ${ }^{14}$ however, the organocatalytic versions of these reactions are of contemporary interest in relation to glycosylation ${ }^{15}$ and in the synthesis of spiroketals. ${ }^{16}$

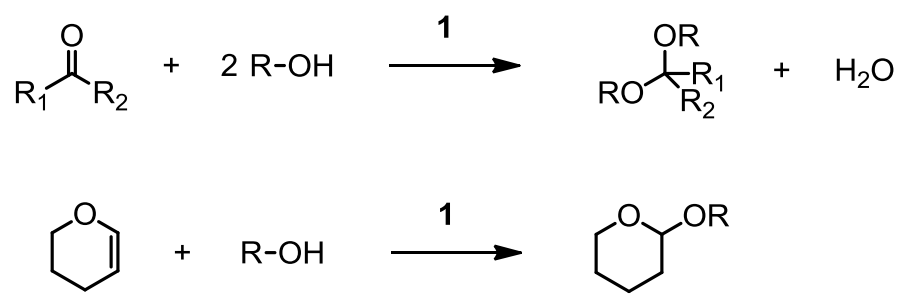

Scheme 1: Acetalization of carbonyls (1) and tetrahydropyranylation of hydroxi functionalities (2) catalyzed by Schreiner's thiourea.

The mechanism of the addition of methanol to 3,4-dihydro-2H-pyran (DHP) was analyzed computationally using DFT and ab initio quantum chemical methods. ${ }^{13}$ The results gave strong support for the proposed mechanistic view, which involved complexation of alcohol with thiourea followed by the addition of the activated alcohol to the unsaturated bond (see HB mechanism in Scheme 2). The addition step is a concerted but asynchronous proton transfer/nucleophilic attack process. The stabilization of the negative charge developing in the transition state was identified as a key factor of the catalytic effect, providing analogy with the enzymatic oxyanion holes. H-bonding interactions were demonstrated to promote the alcohol addition substantially, as 
implied by the barriers obtained for the uncatalyzed and thiourea-catalyzed reactions. The concept of double $\mathrm{H}$ bond catalysis could thus be extended to alcohol activation as well.

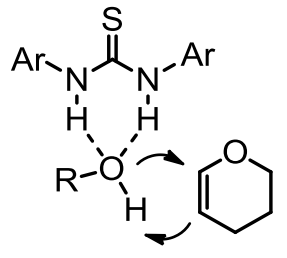

HB mechanism

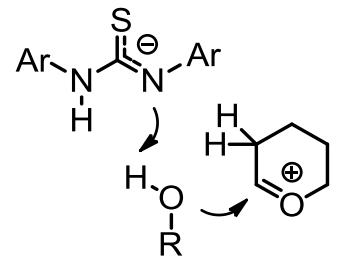

BA mechanism

Scheme 2: Two alternative mechanistic pathways for tetrahydropyranylation of alcohols (HB: hydrogen bonding, BA: Brønsted acid).

In the meantime, the Brønsted acidity of the most popular thiourea-based organocatalysts has been systematically investigated by evaluating the $\mathrm{p} K_{\mathrm{a}}$ values in DMSO. ${ }^{17}$ As a result of the combined effect of the four $\mathrm{CF}_{3}$ groups, the $\mathrm{p} K_{\mathrm{a}}$ of thiourea 1 was found to be fairly low (8.5), "well below the common expectation for a thiourea derivative", as noted by the authors. This value classifies Schreiner's thiourea as a weak Brønsted acid and brings up an alternative mechanistic scenario for the tetrahydropyranylation reaction. Namely, the addition of alcohol may proceed via protonation of DHP by acidic 1 resulting in an oxacarbenium ion intermediate $\left(\mathrm{DHPH}^{+}\right)$, which is then attacked by the alcohol to give the tetrahydropyran product and the catalyst (see BA mechanism in Scheme 2). Depending on the concerted or stepwise nature of these steps, and the relative energies of the involved ion-pair intermediates, this scenario may correspond either to specific or general acid catalysis. ${ }^{18}$ We note, however, that the term "acid catalysis" is sometimes used even for HB-type mechanisms where no proton transfer occurs, which we clearly distinguish here. ${ }^{19}$

In our present work, we aimed to assess the feasibility of the two mechanistic pathways by a comparative computational study. We paralleled the alternative mechanisms by locating the key transition states and related intermediates along the two reaction pathways, which allowed us to estimate the overall activation barriers. Our analysis indicates a clear preference for the Brønsted acid catalyzed pathway. Encouraged by these results, we sought and found experimental evidence in support of the BA mechanism, which is also reported in this paper. As part of these efforts, we demonstrate that the commercially available thiouracil can be used as an organocatalyst in this reaction, and it may thus efficiently promote related transformations as well. 


\section{COMPUTATIONAL DETAILS}

The molecular model we considered to compare the two mechanistic pathways is identical to that used by Kotke and Schreiner in their original work; ${ }^{13}$ i.e., it includes thiourea 1, DHP and a methanol molecule. MeOH is a representative of a family of alcohols tested experimentally for tetrahydropyranylation reactions catalyzed by 1 . The choice for this model substrate is justified by its size (conformational simplicity) and by its acidity as well. Methanol is the most acidic simple aliphatic alcohol, so one expects to get a lower bound for the HB barrier.

We applied density functional theory (DFT) to characterize the electronic structure of the species assumed to be involved in the reaction. The DFT calculations (geometry optimizations and vibrational analysis) were carried out with the dispersion-corrected, range-separated hybrid $\omega$ B97X-D exchange-correlation functional ${ }^{20}$ along with the 6-311G(d,p) polarized triple- $\zeta$ basis set $^{21}$ as implemented in the Gaussian09 package. ${ }^{22}$ The located structures were characterized as energy minima or transition states (TSs) based on the number of imaginary vibrational frequency (zero or one). From the TSs, we followed the intrinsic reaction coordinate (IRC) pathways in both forward and reverse directions, using a Hessian-based predictor-corrector algorithm, ${ }^{23}$ and we identified the related intermediates accordingly. For each located structure, single-point energies were calculated as well with the larger, 6-311++G(3df,3pd) basis. ${ }^{21}$ In all DFT calculations, the ultrafine integration grid was employed to warrant the accuracy of numerical integration.

The thermal and entropic contributions were estimated within the ideal gas - rigid rotor - harmonic oscillator approximation for $T=298.15 \mathrm{~K}$ and $c=1 \mathrm{~mol} / \mathrm{dm}^{3}$ conditions. The solvent effects were taken into account as well by computing the solvation free energies (at the $\omega \mathrm{B} 97 \mathrm{X}-\mathrm{D} / 6-311 \mathrm{G}(\mathrm{d}, \mathrm{p})$ level) via the integral equation formalism variant of the polarizable continuum model (IEFPCM). ${ }^{24}$ The atomic radii and non-electrostatic terms in the IEFPCM calculations were those of the SMD solvation model. ${ }^{25}$ The solvent medium used in the experimental setup does not involve a single solvent (typically a 2:1 ratio of DHP and alcohol was used without any additional solvent), so the choice of the solvent for the implicit solvent model is not trivial. As DHP is not parameterized as a solvent in Gaussian, we used tetrahydrofuran (THF) in our PCM calculations to model the ethereal medium.

The energy values reported in the paper correspond to solution phase Gibbs free energies, which are obtained from $\omega \mathrm{B} 97 \mathrm{X}-\mathrm{D} / 6-311++\mathrm{G}(3 \mathrm{df}, 3 \mathrm{pd})$ electronic energies and all additional terms computed at the $\omega \mathrm{B} 97 \mathrm{X}-\mathrm{D} / 6-311 \mathrm{G}(\mathrm{d}, \mathrm{p})$ level. This computational approach is certainly not expected to provide accurate free energy data mostly due to the empirical ingredients of the solvent model and the approximations employed in the calculation of gas-phase entropic contributions. Furthermore, the alternative acid-base mechanism we examine computationally involves ionic intermediates, which represents further challenge for modeling. In light of a recent critical report that highlighted the limitations of theoretical mechanistic studies (for alcohol-mediated Morita 
Baylis-Hillman reactions), ${ }^{26}$ we performed comprehensive test calculations covering the most relevant approximations (functional, basis set, thermal and entropic contributions, solvent effects). These tests, presented in the Supporting Information, demonstrate that our qualitative conclusions regarding the feasibility of the two alternative mechanisms remain valid at all levels of theory.

\section{RESULTS}

H-bond catalyzed pathways. According to the HB mechanism, the tetrahydropyranylation reaction occurs via a complexed methanol intermediate $(\mathbf{1} \cdot \mathrm{MeOH})$, which attacks the DHP molecule. The half-chair conformation of the enol-ether ring allows two different pathways for the methanol attack (see Figure 1). We examined both pathways and located the transition states of thiourea-assisted alcohol addition.

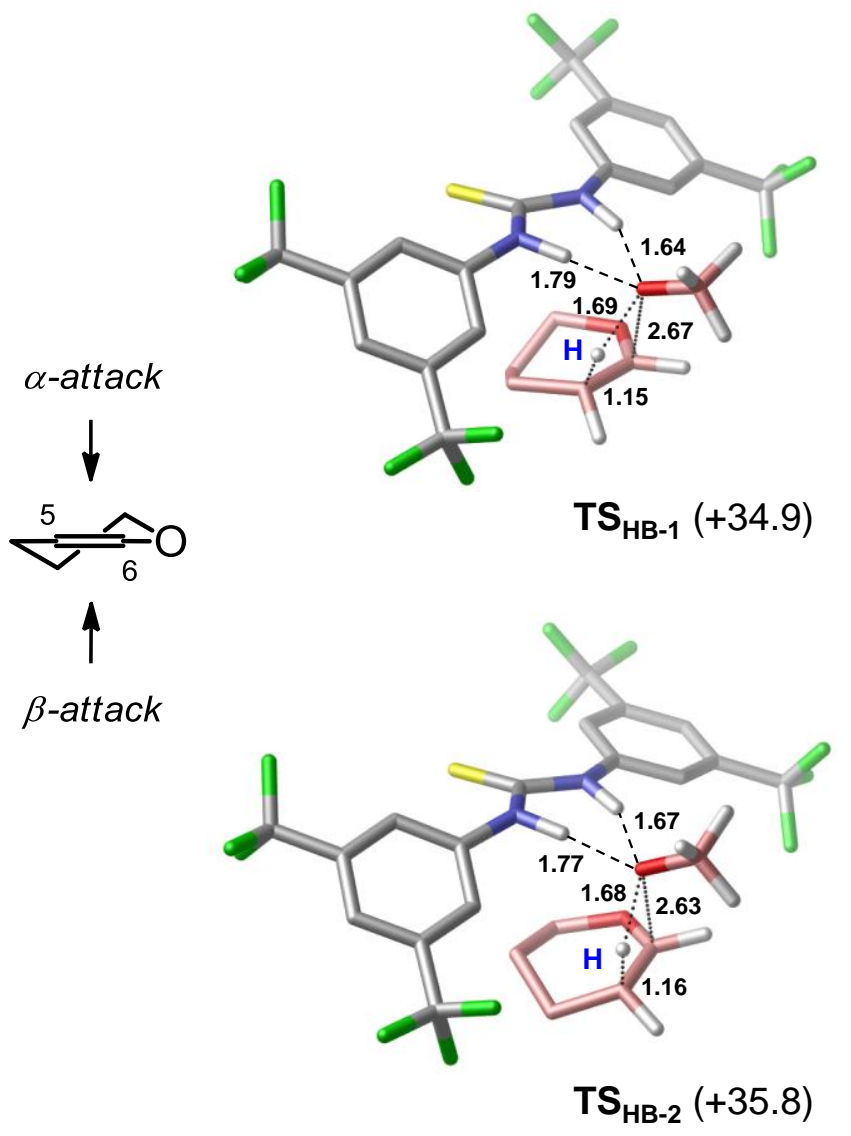

Figure 1: Transition states corresponding to the HB mechanism. Relative Gibbs free energies are given in parentheses (in kcal/mol, with respect to the most stable form of the $\mathbf{1} \cdot \mathrm{MeOH} \cdot \mathrm{DHP}$ ternary complex). Dotted lines represent bonds that are formed or cleaved upon the $\mathrm{MeOH}$ addition process, whereas stabilizing $\mathrm{H}$-bonds are indicated by dashed lines. Carbon atoms of the substrates are highlighted in pink, and only selected $\mathrm{H}$ atoms are shown for clarity. Key bond distances are given in $\AA$. 
Of the two structures, $\mathbf{T S}_{\mathbf{H B}-1}\left(\alpha\right.$-attack) is analogous to that reported by Kotke and Schreiner, ${ }^{13}$ and it is predicted to be slightly favored as compared to $\mathbf{T S}_{\mathbf{H B}-2}$ ( $\beta$-attack). The barriers represented by these TSs are fairly high. ${ }^{27}$ The IRC calculations initiated from the located TSs corroborate that the proton shift to the $\mathrm{C}_{5}$ atom of DHP and $\mathrm{C}_{6}-\mathrm{O}$ bond formation are concerted but highly asynchronous processes (proton transfer is well ahead of methoxide migration). These results are in good agreement with those reported previously. ${ }^{13}$ We note that the stepwise version of the HB mechanism involving a thiourea stabilized methoxide/oxacarbenium intermediate is quite unlikely, because our calculations indicate that the $\mathrm{H}$-bonded $\mathbf{1} \cdot \mathrm{MeO}^{-}$species undergoes a spontaneous deprotonation of the catalyst. This is actually in line with the large difference in Brønsted acidities of $\mathbf{1}$ and methanol ( $\mathrm{pK}_{\mathrm{a}}$ values in DMSO are 8.5 and 29.0, respectively). ${ }^{17,28}$

Brønsted acid catalyzed pathways. In the BA mechanism of reaction 2 shown in Scheme 1, the catalytic cycle begins with a proton transfer from catalyst 1 to DHP. The resulting oxacarbenium ion then reacts with an alcohol, which adds to the electrophilic carbon and returns the proton to the conjugate base of the catalyst. Various reaction pathways corresponding to the three conformers of thiourea $\mathbf{1}$ (shown in Chart 2), and proton transfers to either side of DHP were examined in our study. We employed the same 1/DHP/MeOH termolecular model as above, allowing us to make a direct comparison of the energetics obtained for the two mechanisms. A selection of transition states located along the investigated BA pathways are presented in Figure 2.<smiles>CNC(=S)NC(=S)NC</smiles>

$1-Z, Z$<smiles>NC(=S)NC(N)=S</smiles>

$1-E, Z$<smiles>NC(=S)NC(N)=S</smiles>

$1-E, E$

Chart 2: Conformers of thiourea 1. 


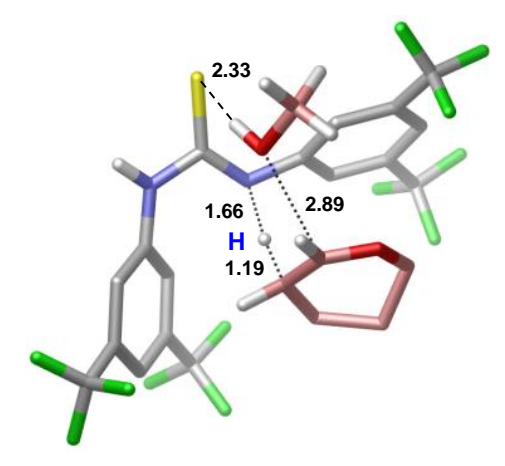

$\operatorname{TS}_{\mathrm{BA}-1}(+28.4)$

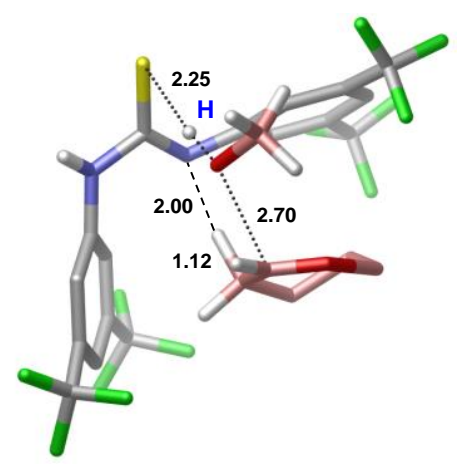

$\mathrm{TS}_{\mathrm{BA}-2}(+29.2)$
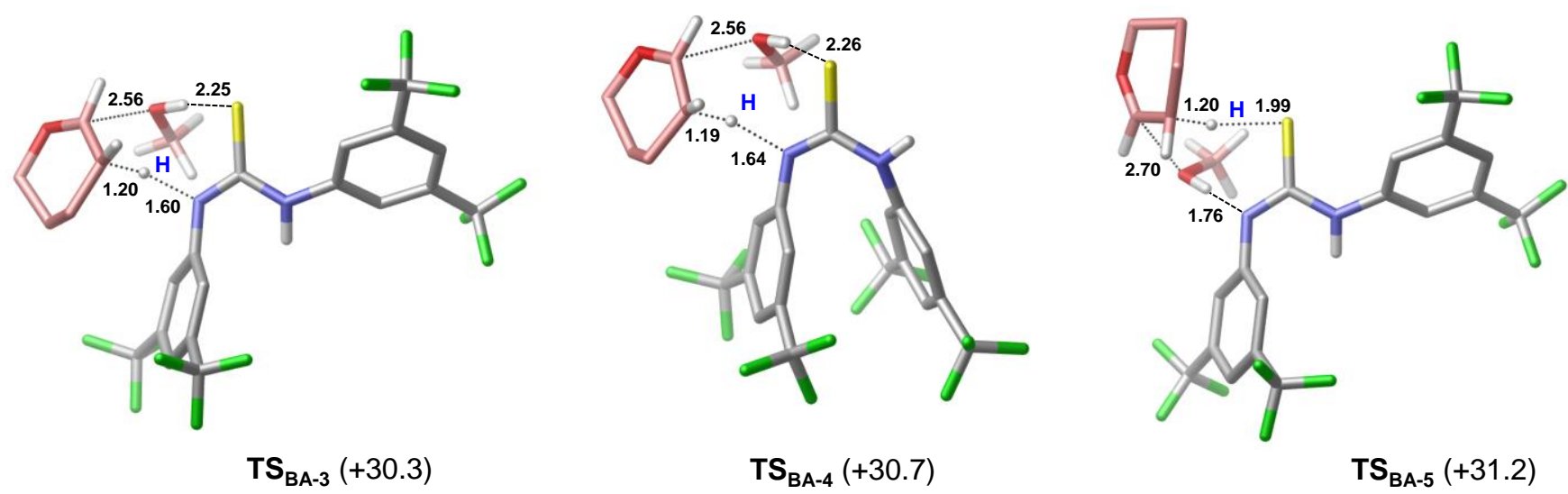

Figure 2: Transition states corresponding to the BA mechanism. Relative Gibbs free energies are given in parentheses (in kcal/mol, with respect to the most stable form of the $\mathbf{1} \cdot \mathrm{MeOH} \cdot \mathrm{DHP}$ ternary complex). Key bond distances are given in $\AA$.

The energetically most favored transition state $\left(\mathbf{T S}_{\mathbf{B A}-1}\right)$ displays the E,Z-orientation of thiourea's N-H bonds, ${ }^{29}$ and the protonation takes place on the $\alpha$-side of the DHP molecule. The proton transfer is coupled with the addition of $\mathrm{MeOH}$, which is initially bound to 1 via an $\mathrm{S} \cdots \mathrm{H}-\mathrm{O}$ type hydrogen bond. The reaction thus occurs in a single step, ${ }^{30}$ but in a highly asynchronous manner, as the $\mathrm{C}-\mathrm{O}$ bond formation and the related proton shift to the $\mathrm{S}$ atom of the catalyst lag behind the DHP protonation process. Importantly, transition state $\mathbf{T S}_{\mathbf{B A - 1}}$ is predicted to be significantly more favored (by $6.5 \mathrm{kcal} / \mathrm{mol}$ ) than $\mathbf{T S}_{\mathbf{H B}-1}$ identified as the most stable TS for the HB mechanism. $^{31}$

For the protonation on the $\beta$-side of DHP (with the same $E, Z$ form of the catalyst), we found a similar and a slightly more favored TS (at $+27.8 \mathrm{kcal} / \mathrm{mol}$; not shown in Figure 2), but in this case, the second phase of the reaction (i.e., the nucleophilic attack of $\mathrm{MeOH}$ ) could be characterized in terms of a distinct TS (TS $\mathbf{B A}_{\mathbf{B A}-2}$ in Figure 2). This latter structure is computed to be at $+29.2 \mathrm{kcal} / \mathrm{mol}$ on the free energy scale, still notably lower than $\mathbf{T S}_{\mathrm{HB}-1}$. The two transition states along this pathway are separated by a high-lying contact ion-pair species $\left(\left[\mathbf{1}_{\mathbf{d p}}\right]^{-} \cdot \mathrm{DHPH}^{+} \cdot \mathrm{MeOH}\right.$, where $\left[\mathbf{1}_{\mathbf{d p}}\right]^{-}$denotes the deprotonated catalyst; see Figure 3, left) being at $+26.9 \mathrm{kcal} / \mathrm{mol}$, which can be regarded as a transient reaction intermediate. In this species, the methanol molecule is bound to the 
ion-pair via $\mathrm{S} \cdots \mathrm{H}-\mathrm{O}$ hydrogen bond. The low barriers defined by the adjacent transition states imply that this reaction pathway represents a borderline between a two-step and a concerted/asynchronous mechanism. ${ }^{32}$

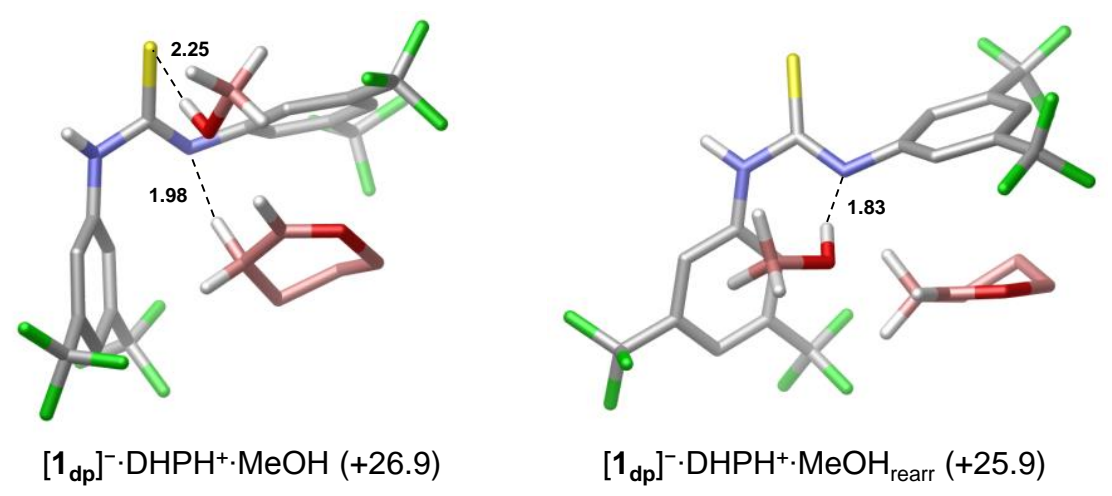

Figure 3: Two different structural arrangements of the ion-pair reaction intermediate identified computationally on the BA pathways. Relative Gibbs free energies are given in parentheses (in $\mathrm{kcal} / \mathrm{mol}$, with respect to the most stable form of the $\mathbf{1} \cdot \mathrm{MeOH} \cdot \mathrm{DHP}$ ternary complex). Key bond distances are given in $\AA$.

The other $\mathrm{N}-\mathrm{H}$ bond of the catalyst in its E,Z-form can also act as a proton donor and may promote the addition of methanol. Indeed, the TS located on this pathway $\left(\mathbf{T S}_{\mathbf{B A}-3}\right.$ at $+30.3 \mathrm{kcal} / \mathrm{mol}$, see Figure 2$)$ describes a one-step concerted/asynchronous addition reaction between DHP and $\mathrm{MeOH}$, similarly to that represented by $\mathbf{T S}_{\mathbf{B A}-\mathbf{1}}$. Analogous transition states related to the reaction with the $Z, Z$ and $E, E$ forms of catalyst $\mathbf{1}$ could also be identified computationally, and they are found to be at about 30-31 kcal/mol in free energy (TS $_{\mathbf{B A}-4}$ shown in Figure 2 corresponds to protonation by $1-E, E)$.

The BA pathways discussed in this section account well for product formation, but the catalyst is transferred into the iminothiol tautomeric form. Alcohol catalyzed tautomerization is a feasible option to regenerate the original form of $\mathbf{1}$ and to close the catalytic cycle. The computed barrier for this process is $6.0 \mathrm{kcal} / \mathrm{mol}$ (for details, see Supporting Information). Alternatively, the thiol isomer might be a catalytically active species as well, so thiourea $\mathbf{1}$ could function as a tautomeric catalyst. ${ }^{33}$ This is exemplified by $\mathbf{T S}_{\mathbf{B A - 5}}$ located for this scenario (see Figure 2), although the computed barrier $(31.2 \mathrm{kcal} / \mathrm{mol})$ is somewhat higher than those presented above.

Competing BA pathways without the involvement of catalyst tautomerization may also exist. For instance, we find that the $\left[\mathbf{1}_{\mathbf{d p}}\right]^{-} \cdot \mathrm{DHPH}{ }^{+} \cdot \mathrm{MeOH}$ ion-pair species can undergo a facile structural rearrangement (migration of $\mathrm{MeOH}$ to form a hydrogen bond with the $\mathrm{N}$ atom of the $\left[\mathbf{1}_{\mathbf{d p}}\right]^{-}$anion; see Figure 3, right), which then provides an alternative $\mathrm{MeOH}$ addition pathway that regenerates $\mathbf{1}$ directly (the proton is shifted to the $\mathrm{N}$ atom). The overall barrier of this pathway is $29.2 \mathrm{kcal} / \mathrm{mol}$ (for details, see Supporting Information). Structural rearrangements 
altering the relative position and orientation of the $\left[\mathbf{1}_{\mathbf{d p}}\right]^{-}$and $\mathrm{DHPH}^{+}$ions may also take place in the contact ionpair species. Our calculations indicate that the dissociation of the $\left[\mathbf{1}_{\mathbf{d p}}\right]^{-} \cdot \mathrm{DHPH}^{+} \cdot \mathrm{MeOH}$ ion-pair (into $\left[\mathbf{1}_{\mathbf{d p}}\right]^{-} \cdot \mathrm{MeOH}$ and $\mathrm{DHPH}^{+}$) cannot be ruled out either as the dissociated state of the ion-pair is predicted to be only $1.9 \mathrm{kcal} / \mathrm{mol}$ less stable than the contact form.

The ion-pair formation may also occur via concerted proton shifts as illustrated in Figure 4 (1 to MeOH and $\mathrm{MeOH}$ to DHP), which represents another possible BA type pathway in the reaction. The barrier computed for this proton shuttle mechanism is $30.6 \mathrm{kcal} / \mathrm{mol}$, which is again comparable to those reported in Figure 2. The corresponding ion-pair species lies at $+28.6 \mathrm{kca} / \mathrm{mol}\left(\right.$ see $\left[\mathbf{1}_{\mathbf{d p}}\right]^{-} \cdot \mathrm{DHPH}^{+} \cdot \mathrm{MeOH}_{\mathrm{PS}}$ in Figure 4). The second step on this pathway of course requires structural rearrangements to enable the $\mathrm{C}-\mathrm{O}$ bond formation (not investigated here).
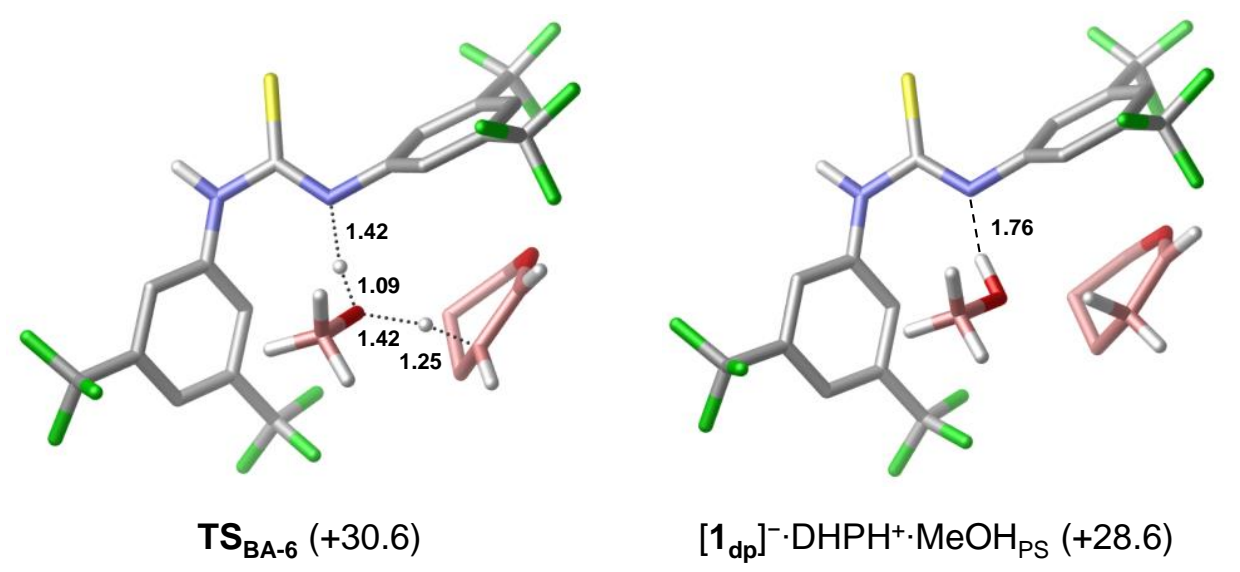

Figure 4: Transition state and the corresponding ion-pair intermediate identified on a BA pathway initiated by a proton shuttle mechanism. Relative stabilities (in $\mathrm{kcal} / \mathrm{mol}$; with respect to the reference state) are given in parenthesis. Key bond distances are given in Å.

1-DHP adducts as off-cycle species. Although the main focus of our present work is to contrast the HB and BA mechanistic models, we examined other conceivable reaction pathways relevant to the catalytic process. For instance, the nucleophilic attack of the deprotonated catalyst $\left[\mathbf{1}_{\mathrm{dp}}\right]^{-}$to oxacarbenium $\mathrm{DHPH}^{+}$is a viable reaction. The calculations reveal that the adduct formation can occur either from the ion-pair intermediate, or via a concerted mechanism with overall barriers similar to methanol addition (28-30 kcal/mol, see Supporting Information). Both types of nucleophilic attacks (i.e., those of $\mathrm{N}$ and $\mathrm{S}$ atoms in $\left[\mathbf{1}_{\mathbf{d p}}\right]^{-}$) lead to fairly stable adduct species as predicted by computations. The most stable forms of these adducts are depicted in Figure 5 . The obtained free energy data suggest that 1-DHP adducts are possible off-cycle species in the catalytic process of 
tetrahydropyranylation; however, the addition of MeOH to DHP is clearly favored thermodynamically $(\Delta G=-6.6$ $\mathrm{kcal} / \mathrm{mol}$ ), so we do not expect the 1-DHP adducts to be present in detectable concentration in the reaction mixture.

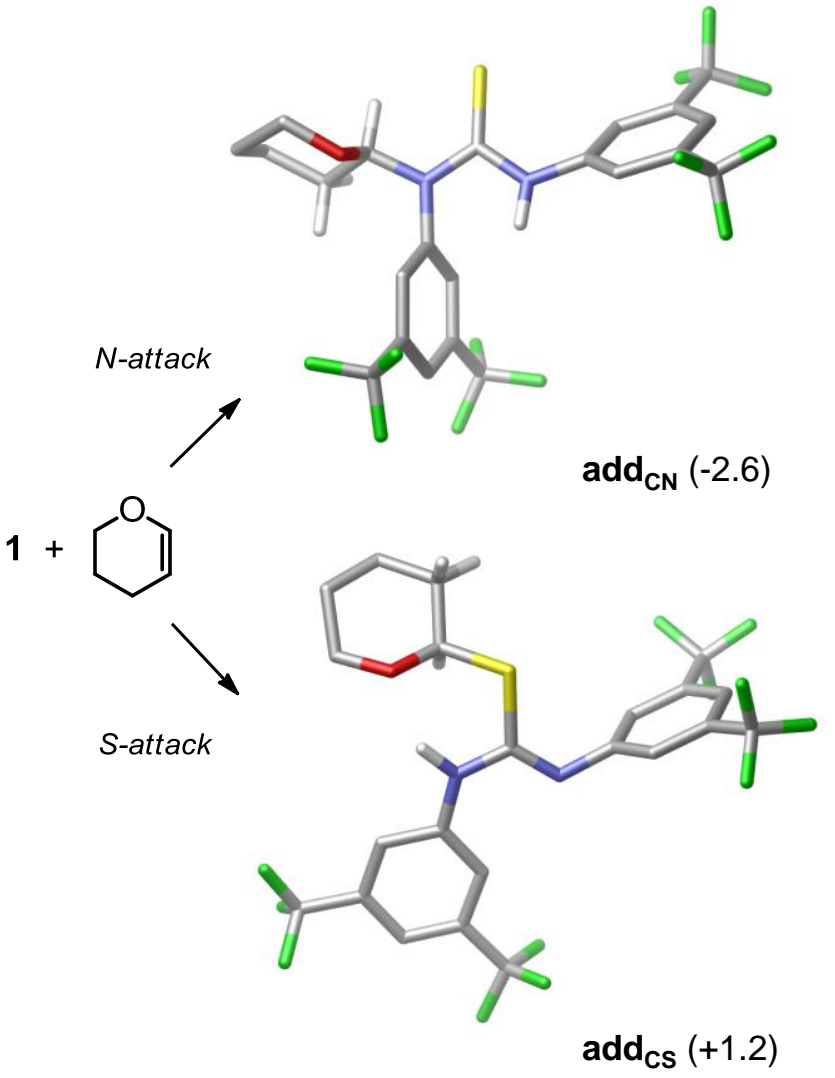

Figure 5: Adduct species formed between 1 and DHP. Gibbs free energies of formation are given in parentheses (in kcal/mol, with respect to $\mathbf{1}+\mathrm{DHP})$.

Computational screening of other catalysts. As illustrated by the transition states depicted in Figure 2, the BA mechanism of thiourea catalysis does not require the parallel orientation of the two N-H bonds as only one of these units is engaged in substrate activation. On the contrary, the concept of thiourea-based H-bond catalysis relies on the cooperative action of two properly aligned N-H groups. In that respect, the two thiourea derivatives shown in Chart 3, i.e., thiouracyl (4) and $N$-methylated Schreiner's thiourea (5) cannot be regarded as ideal HBcatalysts for the DHP + alcohol reaction, but they may operate via the BA mechamism similarly to 1. Computations support this view because the barriers represented by transition states located along the BA pathways in the DHP + MeOH reaction catalyzed by 4 and 5 (Figure 6) fall in the 29-31 kcal/mol range, similarly to that obtained for catalyst $\mathbf{1}$. 


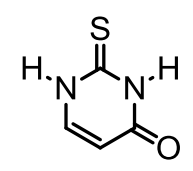

4<smiles>CN(C(=S)Nc1cc(C(F)(F)F)cc(C(F)(F)F)c1)c1cc(C(F)(F)F)cc(C(F)(F)F)c1</smiles>

5

Chart 3: Thiouracyl (4) and $N$-methylated Schreiner's thiourea (5) as potential Brønsted acid catalysts.

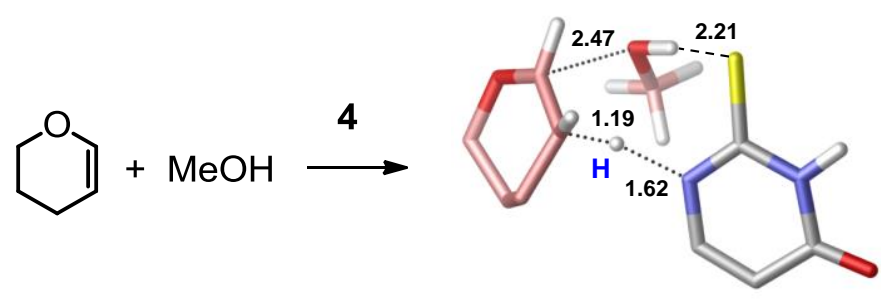

$\operatorname{TS}_{\mathrm{BA}}(4)(+28.6)$

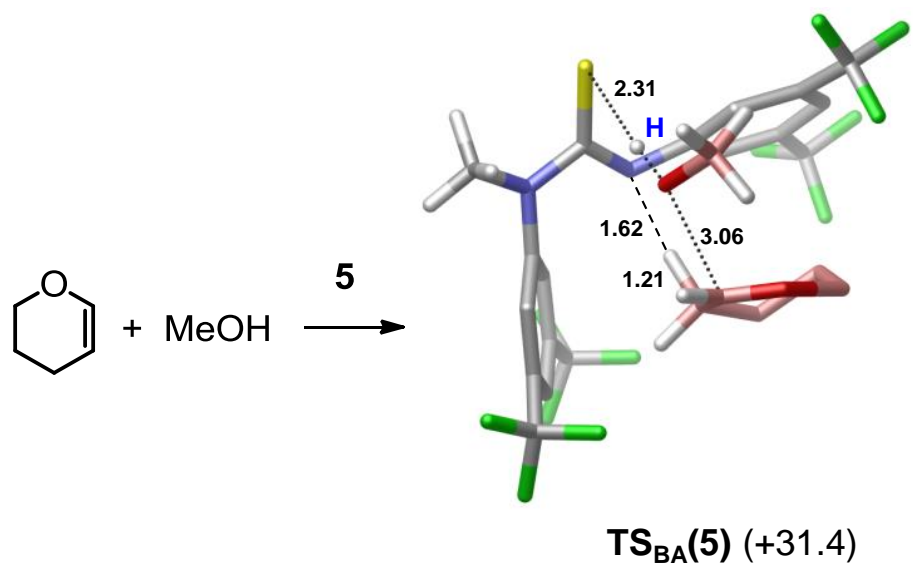

Figure 6: BA type transition states for reactions catalyzed by $\mathbf{4}$ and $\mathbf{5}$. Relative Gibbs free energies are given in parentheses (in kcal/mol, with respect to the most stable form of the related ternary complexes). Key bond distances are given in $\AA$.

Experiments. The computational analysis presented in the preceding sections establishes that the thioureacatalyzed tetrahydropyranylation of alcohols may proceed via Brønsted acid mechanism, and if so, compounds 4 and 5 may also show catalytic activity in these reactions. The latter prediction could actually be confirmed experimentally. DHP was reacted with several alcohols in the presence of compounds $\mathbf{1}, 4$ and $\mathbf{5}$. We selected two alcohols for the comparative studies: benzyl alcohol (6) characterized as the most reactive substrate by Kotke and Schreiner, ${ }^{13}$ and 3-phenyl-propan-1-ol (7), which is also reactive but it contains a longer aliphatic chain. The 
reactions were carried out using the original procedure, and the conversions were determined by GC. The results reported in Table 1 confirm the predicted reactivity of thiourea derivatives $\mathbf{4}$ and $\mathbf{5}$ as they are found to perform similarly to $\mathbf{1}$. Significant conversions are obtained already after 6 hours for both alcohols, and all reactions are completed within 24 hours.

Table 1. Comparison of catalysts 1, 4 and 5 in tetrahydropyranylation of alcohols ${ }^{a}$

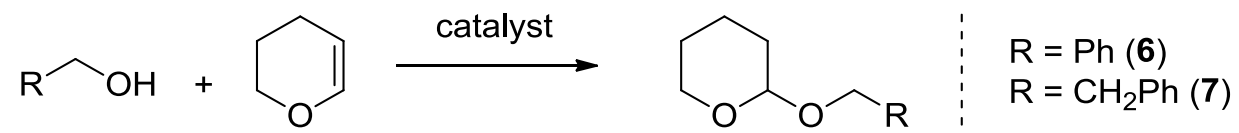

$\begin{array}{llllllll}\text { entry } & \text { catalyst } & \text { load } & \text { alcohol } & T & \text { conv. }(6 \mathrm{~h}) & \text { conv. (12 h) } & \text { conv. (1 day) } \\ 1 & \mathbf{1} & 1 \mathrm{~mol} \% & \mathbf{6} & \mathrm{rt} & 90 \% & 100 \% & 100 \% \\ 2 & \mathbf{1} & 1 \mathrm{~mol} \% & \mathbf{7} & 40{ }^{\circ} \mathrm{C} & 30 \% & 65 \% & 100 \% \\ 3 & \mathbf{5} & 1 \mathrm{~mol} \% & \mathbf{6} & \mathrm{rt} & 19 \% & 73 \% & 100 \% \\ 4 & \mathbf{5} & 1 \mathrm{~mol} \% & \mathbf{7} & 40{ }^{\circ} \mathrm{C} & 96 \% & 100 \% & 100 \% \\ 5^{b} & \mathbf{4} & 0.2 \mathrm{~mol} \% & \mathbf{6} & \mathrm{rt} & 58 \% & 92 \% & 100 \% \\ 6^{b} & \mathbf{4} & 0.2 \mathrm{~mol} \% & \mathbf{7} & 40^{\circ} \mathrm{C} & 76 \% & 100 \% & 100 \%\end{array}$

${ }^{a}$ The reactions were performed with $5 \mathrm{mmol}$ alcohol $(\mathbf{6}, \mathbf{7}), 10 \mathrm{mmol}$ 3,4-dihydro-2H-pyran, and catalysts with indicated loadings. In the absence of catalysts, the product was not formed. The conversion was determined with GC-FID. ${ }^{b}$ For 2 -thiouracil, the loading corresponds to nearly saturated solutions.

Experiments were also designed to examine the stereochemistry of alcohol addition, which is pertinent to the mechanism of catalytic tetrahydropyranylation. In these experiments, we used a conformationally rigid DHP derivative 4-(tert-butyl)-3,4-dihydro-2H-pyran (8) and reacted it with $d^{4}$-methanol in the presence of 1 (Scheme 3).

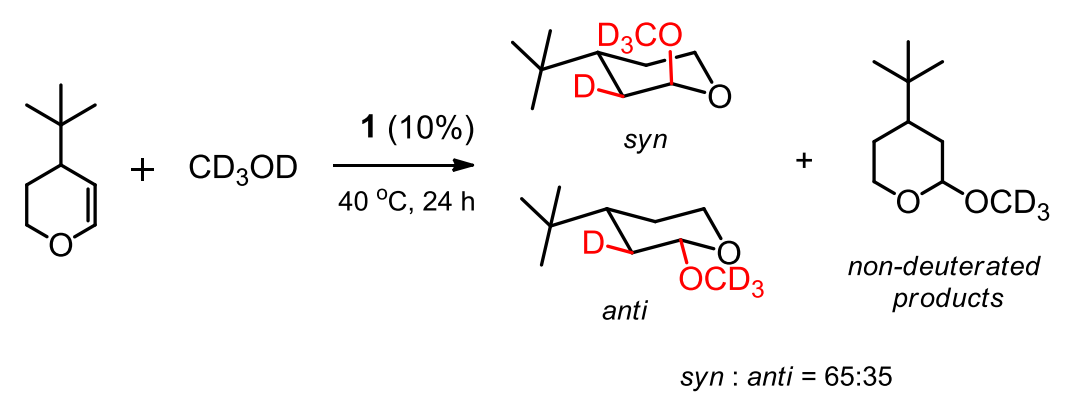

Scheme 3: Addition of deuterated methanol to 8. Products having no deuterium at the carbon of the THP ring originate from 1 and the water content of reagents (see Supporting Information). 
Two different diastereomeric tetrahydropyran products could be identified in this reaction via NMR measurements, which differ in the positions of the methoxy group (syn and anti products). As expected, the protonation of DHP occurs exclusively on the less hindered side of the enol-ether ring ( $D$ and ${ }^{t} \mathrm{Bu}$ are in trans position in both isomers). Although the syn product isomer is found to be in excess, substantial amount of anti product is observed as well. These observations are incompatible with the HB mechanism, which implies only the syn attack of the alcohol molecule due to the strictly concerted nature of the transition states (ion-pair formation can be excluded; see above). On the other hand, facile structural rearrangements of the $\left[\mathbf{1}_{\mathrm{dp}}\right]^{-} \cdot \mathrm{DHPH}^{+} \cdot \mathrm{MeOH}$ ionpair intermediate formed along the BA reaction pathways, or the dissociation of the ion-pair, can give rise to the anti attack. The addition reaction shown in Scheme 3 was repeated by using compounds $\mathbf{4}$ and $\mathbf{5}$ as catalysts as well, and we obtained the same diastereomeric ratios. ${ }^{34}$ Our results are in qualitative agreement with recent observations reported by Zimmerman and Nagorny (see ref. 16e). In that study, tetrahydropyranylation reactions between deuterium-labeled substrates produced an approximately 1:1 mixture of syn and anti products with phosphoric acids or thiourea $\mathbf{1}$ as catalysts. ${ }^{35}$ All these findings point to a common mechanistic action of thiourea derivatives (1, 4 and 5) and phosphoric acids in tetrahydropyranylation reactions, thus providing further support for the BA mechanism. ${ }^{36}$

The computational analysis presented in this paper, namely that the rate-determining transition states correspond to protonation processes, and also that the ion-pair intermediates identified along the BA pathways lie close to these transition states, suggests that the underlying reaction mechanism falls into the category of general acid catalysis. To assess this experimentally, we reacted DHP with $\mathrm{CD}_{3} \mathrm{OD}$ in the presence of deuterated catalyst 1-D $\mathbf{D}_{2}$ (Scheme 4).

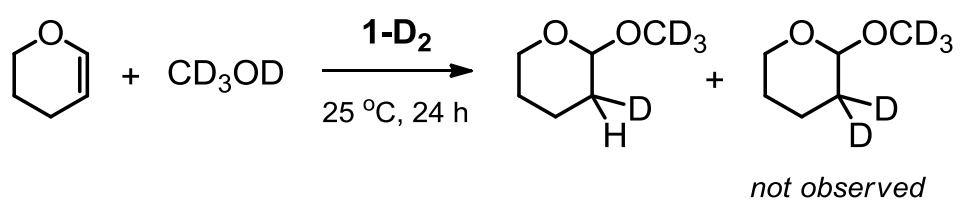

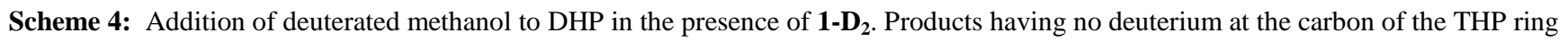
originate from 1 and the water content of reagents (see Supporting Information).

In case of fast equilibrium between the reactants and the ion-pair intermediate (i.e. specific acid catalysis) one expects a mixture of singly and doubly deuterated THP products, however, the latter species could not be detected in our experiments implying that the reaction indeed proceeds under general acid catalysis. 


\section{CONCLUSIONS}

Transition state stabilization through double H-bonding interactions is a generally accepted concept in thiourea organocatalysis. This concept has been previously adopted to interpret the remarkable catalytic effect of Schreiner's thiourea 1 in tetrahydropyranylation of alcohols as well. The computational analysis presented in this article reveals an alternative mechanistic scenario, wherein thiourea $\mathbf{1}$ acts as a Brønsted acid rather than a double H-bond donor. The simple termolecular model used in our (and previous) theoretical studies is certainly insufficient to address the profound mechanistic details of this reactions (this was out of scope of our present work); however, the difference found in the activation barriers related to the two mechanisms is convincingly large to draw conclusions. ${ }^{37}$ Predictions regarding the reactivity of thiourea derivatives $\mathbf{4}$ and $\mathbf{5}$ were confirmed experimentally. These compounds lack the ability to form stabilizing double H-bonding interactions, but they do promote tetrahydropyranylation reactions very similarly to Schreiner's thiourea. The readily accessible thiouracil or its derivatives may thus be considered in organocatalytic applications.

The formation of both syn and anti products in tetrahydropyranylation with deuterated alcohols suggests that the protonation of DHP and the formation of the C-O bond occur in two distinct steps. Some of the Brønsted acid catalysis pathways characterized computationally in our present work (pathways corresponding to $\mathbf{T S}_{\mathbf{B A}-2}$ and $\mathbf{T S}_{\mathbf{B A - 6}}$ ) involve deprotonated catalyst/alcoholate ion-pair intermediates and are thus consistent with this finding. On the other hand, BA pathways featuring a one-step concerted alcohol addition $\left(\mathbf{T S}_{\mathbf{B A}-1}, \mathbf{T S}_{\mathbf{B A}-3}, \mathbf{T S}_{\mathbf{B A}-4}\right.$ and $\mathbf{T S}_{\mathbf{B A - 5}}$ ) can be ruled out based on the above experiment. Further theoretical mechanistic studies employing more advanced computational approaches (including a number of alcohol molecules in the model, and using molecular dynamic simulations) are needed to gain more insight into the reaction mechanism. Double H-bond stabilization remains an invaluable concept in thiourea catalysis; however, the results presented in this paper indicate that the electron deficient thiourea $\mathbf{1}$ may also act as a proton donor (i.e. a Brønsted acid) in certain catalytic processes, particularly in those wherein C-O bond formation (or cleavage) is accompanied by proton transfer (acetalization, glycosylation, or reactions with epoxides and peroxides). These results have practical implications since different strategy is needed for synthetic developments utilizing hydrogen-bond or Brønsted-acid catalysis.

\section{ASSOCIATED CONTENT}

Supporting Information. Details regarding the computational analysis, complete references of the program packages, total energies and Cartesian coordinates for the considered stationary points, and experimental details with NMR spectra. This material is available free of charge via the Internet at http://pubs.acs.org.

\section{AUTHOR INFORMATION}

\section{Corresponding Authors}


varga.szilard@ttk.mta.hu, papai.imre@ttk.mta.hu

\section{ACKNOWLEDGMENTS}

Financial support for this work was provided by the Hungarian Scientific Research Fund (OTKA, grant K-112028). Sz. V. acknowledges a János Bolyai Scholarship from Hungarian Academy of Sciences. We are grateful to Tibor András Rokob for insightful discussions.

\section{REFERENCES}

${ }^{1}$ (a) Berkessel, A.; Gröger, H. (eds.) Asymmetric Organocatalysis. Wiley-VCH: Weinheim, 2005; (b) Taylor, M. S.; Jacobsen, E. N. Angew. Chem., Int. Ed. 2006, 45, 1520; (c) Doyle, A. G.; Jacobsen, E. N. Chem., Rev. 2007, 107, 5713; (d) Pihko, P. M. (ed.) Hydrogen Bonding in Organic Synthesis. Wiley-VCH: Weinheim, 2009.

2 (a) Zhang, Z.; Schreiner, P. R. Chem. Soc. Rev. 2009, 38, 1187; (b) Hof, K.; Lippert, K.M.; Schreiner, P.R. In Science of Synthesis. Asymmetric Organocatalysis 2; Maruoka, K., Ed.; Thieme Stuttgart: New York, 2012; p. 297; (c) Jakab, G.; Schreiner, P.R. In Comprehensive Enantioselective Organocatalysis; Dalko, P. I., Ed.; Wiley-VCH: Weinheim, 2013; Vol 2, p. 315; (d) Fang, X.; Wang, C.-J. Chem. Commun. 2015, 51, 1185

${ }^{3}$ For foundations of the double H-bonding activation concept, see: (a) Hine, J.; Ahn, K.; Gallucci, J. C.; Linden, S.-M. J. Am. Chem. Soc., 1984, 106, 7980; (b) Kelly, T. R.; Meghani P.; Ekkundi, V. S. Tetrahedron Lett., 1990, 31, 3381; (c) Severance, D. L.; Jorgensen, W. L. J. Am. Chem. Soc., 1992, 114, 10966; (d) Etter, M. C.; Urbanczyk-Lipkowska, Z.; Zia-Ebrahimi, M.; Panunto, T. W. J. Am. Chem. Soc., $1990,112,8415$.

${ }^{4}$ (a) Schreiner, P. R.; Wittkopp, A. Org. Lett. 2002, 4, 217; (b) Wittkopp, A.; Schreiner, P. R. Chem. Eur. J. 2003, 9, 407; (c) Schreiner, P. R. Chem. Soc. Rev. 2003, 32, 289.

${ }^{5}$ For a recent review, see: Zhang, Z.; Bao, Z.; Xing H. Org. Biomol. Chem. 2014, 12, 3151.

${ }^{6}$ For a selection of recent contributions, see: (a) Liu, Y. L.; Shi, T. D.; Zhou, F.; Zhao, X. L.; Wang, X.; Zhou, J. Org. Lett., 2011, 13, 3826; (b) Martínez-Muñoz, A.; Monge, D.; Martín-Zamora, E.; Marqués-López, E.; Álvarez, E.; Fernández, R.; J. M. Lassaletta, J. M. Org. Biomol. Chem., 2013, 11, 8247; (c) Tripathi, C. B.; Mukherjee, S. J. Org. Chem., 2012, 77, 1592; (d) Jakab, G.; Hosseini, A.; Hausmann, H.; Schreiner, P. R. Synthesis, 2013, 1635; (e) Burns, N. Z.; Witten, M. R.; Jacobsen, E. N. J. Am. Chem. Soc., 2011, 133, 14578 ; (f) Neumann, M.; Zeitler, K. Chem. Eur. J., 2013, 19, 6950; (g) Yao, Y.; Yu, T. Y.; Zhang, H. B.; Luo, Y. C.; Xu, P. F. Angew. Chem., Int. Ed., 2012, $51,12339$.

${ }^{7}$ For review works on thiourea-based bifunctional organocatalysis, see: (a) Takemoto, Y. Org. Biomol. Chem. 2005, 3, 4299; (b) Siau, W.-Y.; Wang, J. Catal. Sci. Technol., 2011, 1, 1298; (c) see Chapter 6 in ref 1d; (d) Takemoto, Y.; Inokuma, T. In Asymmetric Synthesis II; Christmann, M.; Bräse, S., Eds.; Wiley: New York, 2012; p 233; (e) Serdyuk, O. V.; Heckel, C. M.; Tsogoeva, S. B. Org. Biomol. Chem. 2013, 11, 7051; (f) Fang, X.; Wang, C.-J. Chem. Commun. 2015, 51, 1185.

${ }^{8}$ (a) Okino, T.; Hoashi, Y.; Takemoto, Y. J. Am. Chem. Soc. 2003, 125, 12672; (b) Okino, T.; Hoashi, Y.; Furukawa, T.; Xu, X.; Takemoto, Y. J. Am. Chem. Soc. 2005, 127, 119.

${ }^{9}$ For first developments of cinchona-derived bifunctional thiourea catalysts, see: (a) McCooey, S. H.; Connon, S. J. Angew. Chem., Int. Ed. 2005, 44, 6367; (b) Ye, J.; Dixon, D. J.; Hynes, P. S. Chem. Commun. 2005, 4481; (c) Vakulya, B.; Varga, Sz.; Csámpai, A.; Soós, T. Org. Lett. 2005, 7, 1967; (d) Li, B.-J.; Jiang, L.; Liu, M.; Chen, Y.-C.; Ding, L. S.; Wu, Y. Synlett, 2005, 603; (e) Marcelli, T.; van der Haas, R. N. S.; van Maarseveen, J. H.; Hiemstra, H. Angew. Chem., Int. Ed. 2006, 45, 929.

${ }^{10}$ For mechanistic studies on thiourea-based bifunctional organocatalysis, see: (a) Hamza, A.; Schubert, G.; Soós, T.; Pápai, I. J. Am. Chem. Soc. 2006, 128, 13151; (b) Zuend, S. J.; Jacobsen, E. N. J. Am. Chem. Soc., 2007, 129 , 15872; (c) Hammar, P.; Marcelli, T.; Hiemstra, H.; Himo, F. Adv. Synth. Catal., 2007, 349 , 2537; (d) Zuend, S. J.; Jacobsen, E. N. J. Am. Chem. Soc., 2009, 131 , 15358; (e) Almasi, D.; Alonso, D.; GómezBengoa, E.; Nájera, C. J. Org. Chem. 2009, 74, 6163; f) Tan, B.; Lu, Y.; Zeng,X.; Chua, P. J.; Zhong, G. Org. Lett. 2010, 12, 2682; (g) Zhu, J.-L.; Zhang, Y.; Liu, C.; Zheng, A.-M.; Wang, W. J. Org. Chem. 2012, 77, 9813; (h) Han, X.; Lee, R.; Chen, T.; Luo, J.; Lu, Y.; Huang, K. W. Sci. Rep. 2013, 3, 2557; (i) Azuma, T.; Kobayashi, Y.; Sakata, K.; Sasamori, T.; Tokitoh, N.; Takemoto, Y. J. Org. Chem., 2014, 79, 1805; (j) Qi, Z.-H.; Zhang, Y.; Ruan, G.-Y.; Zhang, Y.; Wang, Y.; Wang, X.-W. RSC Adv., 2015, 5, 34314; (k) Quintard, A.; Cheshmedzhieva, D.; Duque, M.D.S.; Gaudel-Siri, A.; Naubron, J.V.; Genisson, Y.; Plaquevent, J. C.; Bugaut, X.; Rodriguez, J.; Constantieux, T. Chem. Eur. J., 2015, 21, 778; (l) Asari, A. H.; Lam, Y.; Tius, M. A.; Houk, K. N. J. Am. Chem. Soc., 2015, 137, 13191.

${ }^{11}$ For related works on the bifunctional mechanism, see: (a) Kótai, B.; Kardos, G.; Hamza, A.; Farkar, V.; Pápai, I.; Soós, T. Chem. Eur. J., 2014, 20, 5631; (b) Varga, E.; Mika, L. T.; Csámpai, A.; Holczbauer, T.; Kardos, G.; Soós, T. RSC Adv., 2015, 5, 95079 (c) Odagi, M.; Furukori, K.; Yamamoto, Y.; Sato, M.; Iida, K.; Yamanaka, M.; Nagasawa, K. J. Am. Chem. Soc., 2015, 137, 1909; (d) Grayson, M. N.; Houk, K. N. J. Am. Chem. Soc., 2016, 138, 1170.

${ }^{12}$ Kotke, M.; Schreiner, P. R. Tetrahedron, 2006, 62, 434.

${ }^{13}$ Kotke, M.; Schreiner, P. R. Synthesis, 2007, 779.

${ }^{14}$ (a) Wuts, P. G. M. Greene's Protective Groups in Organic Synthesis. $5^{\text {th }}$ Edition, John Wiley \& Sons, Hoboken, 2014; (b) Kocieński, P. J. Protecting Groups. $3^{\text {rd }}$ Edition, Georg Thieme Verlag, Stuttgart, 2004. 
15 (a) Balmond, E. I.; Coe, D. M.; Galan, M. C.; McGarrigle, E. M. Angew. Chem. Int. Ed. 2012, 51, 9152; (b) Mensah, E.; Camasso, N.; Kaplan, W.; Nagorny, P. Angew. Chem., Int. Ed. 2013, 52, 12932; (c) Kimura, T.; Sekine, M.; Takahashi, D.; Toshima, K. Angew. Chem., Int. Ed. 2013, 52, 12131; (d) Balmond, E. I.; Benito-Alifonso, D.; Coe, D. M.; Alder, R. W.; McGarrigle, E. M.; Galan, M. C. Angew. Chem. Int. Ed. 2014, 53, 8190; (e) Peng, P.; Geng, Y.; Göttker-Schnetmann, I.; Schmidt, R. R. Org. Lett., 2015, 17, 1421; (f) Das, S.; Pekel, D.; Neudörfl, J.-M.; Berkessel, A. Angew. Chem. Int. Ed. 2015, 54, 12479.

${ }^{16}$ (a) Zhang, Q.-W.; Fan, C.-A.; Zhang, H.-J.; Tu, Y.-Q.; Zhao, Y.-M.; Gu, P.; Chen, Z.-M. Angew. Chem. Int. Ed. 2009, 48, 8572; (b) Čorić, I.; List, B. Nature 2012, 483, 315; (c) Sun, Z.; Winschel, G. A.; Borovika, A.; Nagorny, P. J. Am. Chem. Soc. 2012, 134, 8074; (d) Nagorny, P.; Sun, Z.; Winschel, G. A. Synlett 2013, 24, 661; (e) Khomutnyk, Y. Y.; Argüelles, A. J.; Winschel, G. A.; Sun, Z.; Zimmerman, P. M.; Nagorny, P. J. Am. Chem. Soc. 2016, 138, 444; (f) Yoneda, N.; Fukata, Y.; Asano, K.; Matsubara, S. Angew. Chem. Int. Ed. 2015, $54,15497$.

17 (a) Jakab, G.; Tancon, C.; Zhang, Z.; Lippert, K. M.; Schreiner P. R. Org. Lett. 2012, 14, 1724; The pK $K_{\mathrm{a}}$ of thiourea 1 was measured in toluene as well: (b) Li, X.; Deng, H.; Luo, S.; Cheng. J.-P. Eur. J. Org. Chem. 2008, 4350.

18 (a) Anslyn, E. V.; Dougherty, D. A. Modern Physical Organic Chemistry. University Science Books, Sausalito, 2006; (b) Carey, F. A.; Sundberg, R. J. Advanced Organic Chemistry, Part A: Structure and Mechanism. Springer: New York, 2007.

${ }^{19}$ For general considerations on the difference between H-bond catalysis and Brønsted acid catalysis, see chapter 2 in ref. $1 \mathrm{~d}$ written by Akiyama, T.

${ }^{20}$ (a) Chai, J.-D.; Head-Gordon, M. Phys. Chem. Chem. Phys. 2008, 10, 6615. (b) Chai, J.-D.; Head-Gordon, M. J. Chem. Phys. 2008, 128, 084106. (c) Grimme, S. J. Comput. Chem. 2006, 27, 1787.

${ }^{21}$ For the 6-311G(d,p) and 6-311++G(3df,3pd) basis sets, see: a) Krishnan, R.; Binkley, J. S.; Seeger, R.; Pople, J. A. J. Chem. Phys. 1980, 72, 650. b) McLean, A. D.; Chandler, G. S. J. Chem. Phys. 1980, 72, 5639. c) Clark, T.; Chandrasekhar, J.; Spitznagel, G. W.; Schleyer, P. v. R. J. Comput. Chem. 1983, 4, 294; d) Frisch, M. J.; Pople, J. A.; Binkley, J. S. J. Chem. Phys., 1984, 80, 3265.

${ }^{22}$ Frisch, M. J.; Trucks, G. W.; Schlegel, H. B.; Scuseria, G. E.; Robb, M. A.; Cheeseman, J. R.; Scalmani, G.; Barone, V.; Mennucci, B.; Petersson, G. A. et al. Gaussian 09, Revision A.02, Gaussian, Inc., Wallingford CT, 2009. See Supporting Information for the complete reference.

${ }^{23}$ (a) Hratchian, H. P.; Schlegel, H. B. J. Chem. Phys. 2004, 120, 9918. (b) Hratchian, H. P.; Schlegel, H. B. J. Chem. Theory Comput. 2005, 1, 61.

${ }^{24}$ Tomasi, J.; Mennucci, B.; Cancès, E. J. Mol. Struct. (Theochem) 1999, 464, 211.

${ }^{25}$ Marenich, A. V.; Cramer, C. J.; Truhlar, D. G. J. Phys. Chem. B, 2009, 113, 6378.

${ }^{26}$ Plata, R. E.; Singleton, D. A., J. Am. Chem. Soc. 2015, 137, 3811.

27 The barriers reported in the paper were computed with respect to the most stable form of interacting reactants $(\mathbf{1}$, DHP and MeOH; see Supporting Information). This choice for the reference level is arbitrary; however, we think it is consistent with the experimental conditions. Namely, the reactions were carried out in a mixture of DHP and alcohol without any additional solvent; therefore, association of the catalyst with the reactants is not expected to demand a significant amount of free energy. We mention that no solution phase Gibbs free energies were disclosed in ref 13; however, the reported standard enthalpies (e.g. $\Delta H_{o}^{*}=+17.7 \mathrm{kcal} / \mathrm{mol}$ ) point to similarly high barriers as well.

${ }^{28}$ Bordwell, F. G. Acc. Chem. Res. 1988, 21, 456.

${ }^{29}$ In line with a previous report (Lippert, K. M.; Hof, K.; Gerbig, D.; Ley, D.; Hausmann, H.; Guenther, S.; Schreiner P. R. Eur. J. Org. Chem. 2012, 5919), the present computational approach predicts the E,Z- and Z,Z-forms of thiourea 1 to be in close equilibrium (for details, see Supporting Information). For a detailed conformational analysis, see Supporting Information

30 Herein, the "single step" refers to the methanol addition process only, and does not imply a termolecular elementary step. Catalyst-alcohol preassociation is an important element of the BA mechanism as well.

${ }^{31}$ Thiourea-catalyzed tetrahydropyranylation reactions of aliphatic alcohols are found to be fairly slow at room temperature (see ref. 13) in spite of the high molar concentration of reactants. The range of barriers associated with the BA mechanism (28-31 kcal/mol) is in qualitative agreement with the observed rates.

${ }^{32}$ The $\left[\mathbf{1}_{\mathbf{d p}}\right]^{-} \cdot \mathrm{DHPH}^{+} \cdot \mathrm{MeOH}$ species and the adjacent transition states become slightly more stable when the geometry optimizations are carried out with the explicit solvent model (for details, see Supporting Information).

33 Rony, P. R. J. Am. Chem. Soc. 1969, 91, 6090.

${ }^{34}$ The unvaried diastereomeric ratio (and deviation from 1:1 ratio) might be related to the presence of bulky ${ }^{\mathrm{t}} \mathrm{Bu}$ substituent on DHP.

${ }^{35}$ The nonselective formation of syn and anti products described in ref 14e were interpreted in terms of a relatively long-lived solvent-separated oxacarbenium/stabilized alkoxide ion-pair intermediate. However, as noted above, our calculations predict the $\mathrm{H}_{-}$-bonded $\mathbf{1}^{\cdot} \mathrm{MeO}^{-}$species to be unstable (it transfers into $\left[\mathbf{1}_{\mathbf{d p}}\right]^{-} \cdot \mathrm{MeOH}$ ).

${ }^{36}$ Interestingly, carboxylic acids with similar $\mathrm{p} K_{\mathrm{a}}$ values do not seem to promote the reaction of DHP with alcohols. For an example (reaction in the presence of chloroacetic acid) see ref. 16e. Experiments with 4-nitro-benzoic acid gave similar results (no reaction; see Supporting Information). It thus appears that the relative $\mathrm{p} K_{\mathrm{a}}$ values of potential Brønsted acid catalysts cannot be regarded as a sole descriptor to characterize the catalytic activity in the present reaction. More efforts are needed to reach sufficient understanding.

${ }^{37}$ Calculations carried out for a model extended with an additional methanol molecule reveal equally high preference for the BA mechanism (for details, see Supporting Information). 
TOC graphics:

thiourea catalysis
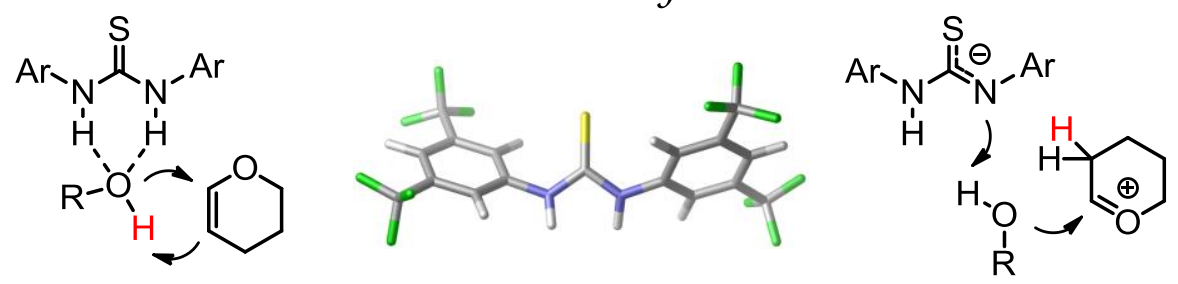

HB mechanism

BA mechanism 